\title{
40 jaar "Lutje P.J.G.", een lutje geschiedenis
}

\author{
W. Goudsmit ${ }^{*}$
}

\section{Inleiding}

Dit jaar bestaat het Groningse Lutje P.J.G. ofwel het kleine Psychiatrisch Juridisch Gezelschap 40 jaar. Het lijkt zinvol om bij deze gelegenheid kort op de geschiedenis van het 'Lutje', zoals het Lutje P.J.G. wordt genoemd, in te gaan. Hoe en waarom is het ontstaan, welke thema's hielden ons bezig en hoe moet het verder? Achtereenvolgens wordt besproken hoe de forensischpsychiatrische situatie destijds in het land en speciaal in Groningen was, hoe het tot de oprichting van het Lutje is gekomen en hoe het Lutje uitgroeide tot een levendige gesprekskring. De titels van de gehouden voordrachten laten zien wat ons destijds en later bezighield: problemen van toen die ook thans na veertig jaar niet allemaal opgelost zijn. Tenslotte zal een blik op de toekomst worden gericht: wat staat ons te wachten kort voor het begin van een nieuwe eeuw? Dit artikel kan niet meer zijn dan een summier overzicht. Om verwarring te voorkomen zal het Psychiatrisch Juridisch Gezelschap P.J.G. worden genoemd, de Groningse gesprekskring het Lutje.

\section{De periode na W.O.II}

Om het ontstaan van het Lutje duidelijk te maken is het noodzakelijk een blik te werpen op de forensisch-psychiatrische en strafrechtelijke situatie in ons land na de bevrijding. De specialistische opleiding tot zenuwarts duurde in die tijd slechts drie jaar. Pas later werd de opleiding terecht gescheiden in de disciplines psychiatrie en neurologie. De assistent in opleiding hoorde in die tijd zeer weinig over forensische psychiatrie; de opleiding bestond vrijwel uitsluitend uit patiëntenzorg. De theoretische kennis moesten de arts-assistenten verkrijgen door lezen van de vakliteratuur en het verplicht bijwonen van de colleges van de hoogleraar en van de refereeravonden. Supervisie, zoals wij die thans sedert vele jaren kennen, bestond destijds nog nauwelijks;

*Zenuwarts en em. hoogleraar Forensische Psychiatrie RU Groningen. 
psychotherapie werd als het ware wild en 'free-lance."' gedaan, na zelfstudie uit boeken en tijdschriften. Dit gebeurde echter wel met veel overgave. Behalve de zeer langdurige psycho-analytische opleiding bestond er destijds nauwelijks enige scholing in psychotherapie; de techniek van de hypnose kon in Amsterdam in een veertiendaagse cursus geleerd worden. Het gebeurde nog dat sommige gevestigde zenuwartsen in de bagageruimte van hun auto een electroshocktoestel meenamen om daarmee depressieve plattelandsbewoners ter plaatse te behandelen. In de psychiatrische inrichtingen, destijds nog krankzinnigengestichten genoemd, heersten letterlijk vooroorlogse toestanden: de patiënten hadden vrijwel geen rechten, de electroshock werd naast behandeling ook als strafinstrument gebruikt en de patinten droegen nog gestichtskleding. Tot 1947 was in sommige strafinrichtingen de celkap nog verplicht; zonder deze Ku-klux-clan-achtige vermomming was het de gedetineerden niet toegestaan om zich buiten hun cel te begeven. Kraus (1956) noemde de gevangenissen en inrichtingen scholen van ontucht en misdaad en de tweede Beginselenwet van 1951 was in de praktijk nog grotendeels een wensdroom. Wel waren in de gevangenissen al sociaal-ambtenaren aangesteld. De humanistische geestelijke verzorger deed bovendien zijn intree. De universitaire psychiatrie was echter nog volop in ontwikkeling; er moest een achterstand van vijf jaar bezettingsisolement worden ingehaald.

\section{Ontwikkeling}

De klinische psychologie en de psycho-analytische zienswijze kregen in die tijd langzamerhand meer invloed op de continentale psychiatrie. Ook de sociale psychiatrie groeide uit van een beperkt nazorg-controlesysteem naar een op de mens in de samenleving gerichte zorg-psychiatrie. De namen van de Groningse hoogleraren van der Scheer, Kraus, Baan, van Dijk en Giel kunnen hier niet onvermeld blijven. Nieuwe wetenschappelijke normen werden ontwikkeld en met het preparaat Largactil begon het tijdperk van de thans niet weg te denken psychofarma-therapie. De biologische psychiatrie stond in de kinderschoenen en ging een toen nog nauwelijks voorstelbare ontwikkeling tegemoet.

Tegelijkertijd werd de kinderpsychiatrie volwassen. Th. Hart de Ruyter ontwikkelde het drie-fasenmodel, dat hij toepaste bij de klinische behandeling van zwaar emotioneel verwaarloosde kinderen en jeugdigen. Dit model hield in dat in de eerste fase van de behandeling voornamelijk getracht werd om de contactmogelijkheden van de patiënt te helpen ontwikkelen. In de volgende fase 
kwam de realiteitstoetsing in het middelpunt van de therapie te staan. Pas in de derde fase vond de behandeling van onbewuste processen plaats. Dit model werd, wel enigszins gemodificeerd, voorbeeld voor de behandeling in het Groningse 'noodasyl', sedert 1962 de Dr. S. van Mesdagkliniek.

Van nauwelijks te overschatten betekenis was de oprichting van de psychiatrische observatiekliniek van het gevangeniswezen in Utrecht, die onlosmakelijk verbonden is met de naam van P.A.H. Baan. Zorgvuldig multidisciplinair onderzoek maakt een patiëntgerichte behandeling pas echt mogelijk.

Ook de reclassering kreeg een nieuw gezicht. F.S. Meyers en na hem G.TH. Kempe en J. Kloek waren de wegbereiders voor een moderne nazorg van voorwaardelijk in vrijheid gestelde en ontslagen gevangenen. J.M. van Bemmelen was reeds in 1923 in Groningen gepromoveerd op het proefschrift met de titel Van zedelijke verbetering tot reclassering. De vernieuwing van het gevangeniswezen is sterk verbonden met de namen van J.P.W. Pompe en H. van der Hoeven. In 1955 werden de psycho-therapeutische centra Groot Batelaer van het Leger des Heils te Lunteren en de Dr. Henry van der Hoevenkliniek te Utrecht geopend.

Het is opvallend dat het ministerie van defensie juist vlak na de oorlog - een tijd waarin psychotherapie vrijwel uitsluitend was weggelegd voor welgestelde burgers - het therapeutische trainingscentrum Austerlitz opgericht heeft en dat het ministerie van justitie in Lunteren en Utrecht mogelijkheden schiep voor de behandeling van ernstig neurotisch gestoorde en verminderd toerekeningsvatbaar geachte delinquenten. Austerlitz werd na enkele jaren door defensie weer opgeheven. De therapeutische centra voor psychisch gestoorde delinquenten, thans forensisch-psychiatrische klinieken, breidden zich echter uit en zijn heden een onmisbaar bestanddeel van de zorg voor en de behandeling van gedetineerden.

\section{'Noodasyls'}

Het eerste gevolg van deze ontwikkelingen was een explosieve toename van het aantal ter beschikking van de regering gestelden. De huizen van bewaring werden overspoeld door 'passanten' die daar moesten wachten - soms meer dan een jaar - om geplaatst te worden in één van de therapeutische instituten. 
Om in deze situatie enige verlichting te brengen, werden in de gevangenissen in Den Haag en in Groningen zogenaamde 'noodasyls voor psychopathen' geopend. Helaas werden aan deze afdelingen geen mogelijkheden voor een adequate behandeling verbonden. In Groningen hield een psychiater één middag in de week zitting om ontevreden patiënten te woord te staan en verlengingsadviezen te schrijven. De patiënten onderscheidden zich van de 'gewone gedetineerden' door een $P$ (van 'psychopaath') op het naamplaatje op de stalen deur en door het feit dat zij voor onbepaalde tijd waren opgesloten. In plaats van V.I. bestond voor hen de mogelijkheid van proefverlof; die mogelijkheid was destijds echter nog niet in de wet vastgelegd.

Maar ook de huidige regeling is geenszins bevredigend. Ter beschikking gestelden werden door de overige gedetineerden en ook door de meeste personeelsleden als psychisch minderwaardig beschouwd. Niet zelden werden ze gediscrimineerd. Verder waren er weinig verschillen tussen beide groepen. Een uitgebreid interdisciplinair onderzoek, opgezet door de hoogleraren Kraus en Röling, zou later aantonen dat er inderdaad psycho-pathologisch en psychosociaal nauwelijks verschillen bestonden tussen de groep recidiverende gevangenen en de ter beschikking gestelde delinquenten (Van Rooy en medewerkers, 1957).

In het najaar van 1953 werd mij verzocht de psychiatrische zorg in de gevangenis en in het noodasyl te Groningen op mij te nemen. Op deze taak was ik onvoldoende voorbereid. Alleen in dienst van de Sectie Geestelijke Gezondheidszorg van de Koninklijke Landmacht had ik als 'reserve officier van gezondheid' iets over forensische psychiatrie en het uitbrengen van een psychiatrische rechtbankexpertise geleerd. Het spreekt haast vanzelf dat ik onmiddellijk lid werd van het P.J.G.. De voordrachten die ik daar hoorde waren voor mij van grote waarde.

\section{P.J.G.}

In 1957 vierde het P.J.G. zijn 50-jarig bestaan. Ter gelegenheid hiervan verscheen er een ook vandaag nog actueel gedenkboek. De publikaties van het P.J.G. geven een bijzonder goede indruk van wat er in die jaren in ons land op sociaal, psychiatrisch en strafrechtelijk gebied gebeurde en wie de 'acteurs' in dit boeiende schouwspel waren. In mijn herinnering was het P.J.G. in die tijd een haast hiërarchisch gestructureerde groep. Op de voorste 
rij zaten naast de gastheer L. van der Horst de andere toonaangevende hoogleraren. Van de overige aanwezigen mengden zich vrijwel uitsluitend diegenen in de discussie die reeds naam gemaakt hadden. Ik heb in die tijd veel interessante en ook aardige mensen leren kennen. Met veel respect denk ik terug aan o.a. H.C. Rümke, J.M. van Bemmelen, G.E. Langemeijer en N. Muller, de geestelijke vader van het Maandblad voor Berechting en Reclassering.

\section{Oprichting Lutje P.J.G.}

Mij viel spoedig op dat ik, voorzover ik kon zien, op die zaterdagochtenden in de Valeriuskliniek vrijwel steeds de enige psychiater uit Groningen was. Ik sprak hierover met mijn leermeester Kraus en stelde voor om in Groningen een vergelijkbare gesprekskring te organiseren. Kraus reageerde zeer positief en ook Röling was direct met het idee ingenomen. Zo ontstond het Lutje. Tot de eerste deelnemers behoorden o.a. W.K. van Dijk, J.L.H. Cluysenaer, J.W. Reicher en Anna C. Bleeker, die de secretarisfunctie op zich nam. Zij werd later opgevolgd door Mr. Nel Duyvendak, die toen ook het toezicht op de inkomsten en uitgaven van het Lutje kreeg. Duyvendak was één van de trouwste deelnemers van het Lutje. Zij werd na haar onverwachte dood opgevolgd door Mr. Wiene F. van Hattum.

Aangezien het Lutje nooit een vereniging is geweest, heeft het nooit een bestuur en derhalve ook geen gekozen penningmeester gehad. Wel functioneert er, informeel, een voorzitter of gespreksleider. Hiermee tonen we aan dat met een goed particulier initiatief en enthousiast amateurisme veel te bereiken valt.

Het doel van de gespreksgroep, die pas enige tijd later de - door Anna C. Bleeker bedachte - naam Lutje kreeg, was dat psychiaters, juristen, psychologen en reclasseringswerkers elkaar beter zouden leren kennen en elkaars vak beter zouden leren begrijpen. Op deze wijze zou een beter functioneren en een betere samenwerking bereikt kunnen worden.

\section{Forensische psychiatrie}

Een betere samenwerking was destijds geen overbodige luxe. Veel forensisch-psychiatrische rapporten uit die tijd verdienden namelijk nauwelijks 
die naam. Er waren toen psychiaters die een patiënt 5 à 10 minuten 'gezien' hadden, om daarna in een rapport te schrijven dat onderzochte een 'psychopaath' was. Deze 'diagnose' werd soms nog onderstreept met toevoegingen als onverbeterlijk, hysterisch of degeneratief. Ik herinner me ook nog de term geen zalf aan te strijken. De betreffende psychiaters hadden hun cliënten inderdaad gezien, maar ze hadden verzuimd een behoorlijk onderzoek te doen. Misschien hebben zij dat in hun tijd ook nooit geleerd. Het zal geen verbazing wekken dat de door deze psychiaters geschreven rapporten steeds sterk op elkaar leken.

Eén keer heeft een rechter-commissaris mij verzocht de rapporten korter te houden, dan hadden hijzelf en de leden van de rechtbank minder tijd nodig om 'dat allemaal' te lezen; bovendien zou ik in dezelfde tijd meer rapporten kunnen schrijven. Ook werd mij gevraagd de diagnose in de toen gebruikelijke terminologie weer te geven, dus ofwel psychopathie ofwel hysterie of krankzinnigheid te constateren; dan zou de rechter meteen begrijpen wat er aan de hand was.

Wat zou de rechter indertijd gedacht hebben indien hij een hedendaags rapport van het Pieter Baan Centrum had kunnen lezen? Er waren toen nog de 'psychiatrisch toezichthouders', die de onder toezicht gestelden om de drie maanden gedurende enkele minuten vermanend toespraken, om daarna te rapporteren. De reactie van Baan op de klacht van psychiaters over de in hun ogen te geringe vaste vergoeding van 48 gulden per jaar was: "Dat is voor wat ze daarvoor doen nog veel te veel".

Ook in de gevangenis was er nog weinig begrip voor de psychiater. Ik kan mij een droom herinneren van de toenmalige directeur van de gevangenis en het noodasyl, een onkreukbare en zeer gevoelige man: Hij zag zeven (!) psychiaters door zijn inrichting lopen en werd verschrikkelijk bang; waren het zeven tijgers geweest, dan had het hem niet zoveel kunnen schelen.

Bij de meeste reclasseringsverenigingen was het werken in teamverband met andere disciplines ook nog een onbekend begrip; de forensische psychologie stond nog in de kinderschoenen. Wel was in 1924 door F.S. Meyers de Centrale Vereniging tot behartiging van de belangen van geestelijk gestoorden in de maatschappij opgericht. Deze vereniging had na de invoering van de 'psychopatenwetten' ook de nazorg voor tbr-gestelden op zich genomen. Onder de bezielende leiding van J. Kloek werd de Vereniging gemoderniseerd.

Het was het idee van Kraus om in Groningen bij 'Het Genootschap' - dat toen nog officieel Genootschap tot zedelijke verbetering der gevangenen heette met een experiment te beginnen. Dit experiment hield in dat aan het bureau 
van de reclassering een psychiater, een psycholoog en een jurist werden verbonden, die als team samen moesten werken. Het idee was ontstaan naar het voorbeeld van een M.O.B. (Medisch Opvoedkundig Bureau), waar niet de kinderpsychiater maar een maatschappelijk werker de eindverantwoordelijkheid droeg. Het experiment van Kraus mag volledig geslaagd worden genoemd. Binnen enkele jaren was het aanvankelijke experiment dagelijkse routine geworden. In die tijd werden recidiverende zedendelinquenten nog vaak, nadat het ministerie van Justitie daarvoor toestemming had verleend, gecastreerd. De Amsterdamse publicist Meyer Sluyser (1967) zou later een objectief en aangrijpend verslag publiceren van een onderzoek naar de gevolgen van castratie. Zijn boek is een aangrijpend 'document humaine' geworden.

\section{0 jaar Lutje}

Wij zullen ons thans beperken tot het wel en wee van het Lutje in de 40 jaar van zijn bestaan. Zoals reeds opgemerkt ging het om de ontmoeting van juristen, psychiaters, psychologen en maatschappelijk werkers. De combinatie van een voordracht met een daaropvolgende discussie was het middel om het doel te bereiken. Feitelijk ging het primair niet om discussiëren, maar om met elkaar in gesprek te komen: een gesprek heeft meer inhoud dan een discussie. Het is persoonlijk en de deelnemer behoeft geen gelijk te krijgen. Het gesprek kent geen strijd en derhalve geen winnaars of verliezers. Je kunt in een gesprek veel meer zeggen dan in een discussie mogelijk is. 'Alles zeggen' gebeurt onder mensen vermoedelijk slechts bij uitzondering, want het kan een onnodige kwetsing van andere gespreksparticipanten inhouden. Voor mijzelf hadden de voordrachten en gesprekken bovendien de duidelijke functie van bijscholing. Daarbij kwam de gezellige, vaak hartelijke sfeer van de groep.

$\mathrm{Na}$ de voltooide nieuwbouw van de psychiatrische kliniek vergaderde het Lutje gedurende vele jaren in het klein auditorium van de nieuwe psychiatrische kliniek; sedert mei 1992 geniet het Lutje gastvrijheid in de Dr.S. van Mesdagkliniek. Over de eerste vier jaar vond ik nauwelijks aantekeningen. De vroegste aantekeningen stammen uit 1959; het Lutje was toen een kleine privé club, die vier keer per jaar in de bibliotheek van de oude Psychiatrisch-Neurologische Kliniek bij elkaar kwam. Kenmerkend was en is nog steeds de onbureaucratische structuur, als er al van structuur sprake is. Het Lutje kent nog steeds geen reglement en de enige enigszins officiële functie is die van de penningmeester. 
In 1985 werd het 30-jarige bestaan van het Lutje feestelijk gevierd. Ter gelegenheid daarvan hebben J.W. Reicher, J. Remmelink en Th.W. van Veen een boek samengesteld met geactualiseerde teksten van voordrachten die in de voorafgegane jaren werden gehouden. Het boek kreeg de bijzonder toepasselijke titel Verantwoordelijk voor mensen.

De eerste bewaard gebleven titel van de voor het Lutje gehouden voordrachten is die van G. Overdiep. De voordracht ging over de "rechtsbescherming van de feitelijke verhouding tussen het onwettige kind en zijn ouders, gezien in het licht dier verhouding in Drenthe." Uit mijn eerste tijd bij het Lutje herinner ik mij nog de voordrachten van B.V.A. Röling over het tribunaal voor oorlogsmisdadigers in Tokio, van P.E. Boeke over de betekenis en waarde van psychologische tests, van Th. Hart de Ruyter over opvang en behandeling van ernstig emotioneel verwaarloosde kinderen, van H. van Rooy over het vergelijkend onderzoek van recidiverende delinquenten en ter beschikking van de regering gestelden in het Groninger noodasyl voor psychopaten en van P.A.H. Baan over de filosofie achter de behandeling in de Dr. Henry van der Hoevenkliniek. Niet alle voor het Lutje gehouden voordrachten zijn nog bekend. Wel is bekend dat in de jaren zestig een hoofdambtenaar van het Ministerie van Justitie, specialist in pornografie, werd gevraagd een voordracht over dit onderwerp te houden. Hij lichtte zijn voordracht toe met films en dia's. Helaas zijn hierover geen gegevens meer bewaard gebleven. Het was immers interessant geweest om te zien hoe men indertijd over pornografie dacht. De opkomst op die avond was duidelijk hoger dan anders; het kan niet verbazen dat de 'show' reeds spoedig verveelde.

\section{Titels van voordrachten: 1959-1994}

Een volledig overzicht van de titels van gegeven lezingen is niet haalbaar. Hieronder zijn achterhaalde titels weergegeven. Het is mogelijk dat sommige data van deze titels niet correct zijn; op sommige stukken ontbreekt namelijk de datum.

17-02-1959 G. Overdiep en G.Mulder: Wat brengt de rechter er toe om aan een psychiater opdracht te verlenen voor een onderzoek naar de geestvermogens van een verdachte?

09-12-1959 W. Goudsmit: Over verminderde toerekeningsvatbaarheid.

10-01-1961 H. van Arkel: Gevangenis en deskundige.

15-04-1961 W.A. Hofman: De praktijk van het psychiatrisch toezicht. 
24-09-1964 J.M. de Jonge: Dronkenschap en delict.

23-09-1965 H. Stutte: Über klinische Behandlung von emotional schwerst gestörten Jugendlichen.

09-12-1965 Mw. P. Meuleman: Hulpverlening aan de ongehuwde moeder en haar kind.

28-04-1966 Spreker niet te achterhalen: Problemen van het verkeer, problemen van de politie.

02-03-1967 J.W. Reicher: Psychotherapie bij delinquenten.

26-10-1967 H. Blijham: Het abortusvraagstuk.

18-01-1968 H.J. Krauweel: Verslaving en behandeling.

13-06-1968 C. Rümke: Kinderen en echtscheiding.

03-10-1968 G. Overdiep: Ervaringen als rechter.

12-12-1968 J. Mein: Ervaringen bij het O.M.

08-05-1969 L.H.C. Hulsman: Gedachten over hervorming van het strafrecht.

25-09-1969 A.C. Geurts: Criminologie en penitentiair recht.

27-11-1969 G. Mik: Jeugdproblemen vroeger en nu.

10-09-1970 W. Nieboer: De nota psychopathenzorg.

05-11-1970 H. van Praag: Marihuana, Folklore en wetenschap.

04-02-1971 Open discussie: Hoe gaan we verder met het Lutje.

22-04-1971 W. Nieboer: De toerekening in het strafrecht.

09-09-1971 Th.W. van Veen: Overtuigingsdelinquenten.

11-11-1971 Tj. Jonsgsma: Inspraak en uitspraak.

??-09-1972 R.C. Hoekstra: Het begrip catathyme crisis.

27-09-1973 R.W. Jongman: Opmerkingen over agressie.

29-11-1973 J.P. Kruyt: Over de biologische benadering van agressie.

14-02-1974 W.J. Reicher: Agressie en psychotherapie.

02-05-1974 G. Steenmeijer: Problemen van de politie ten opzichte van agressief gedrag.

24-09-1974 D.W. Steenhuis: Gedachten over generale preventie.

21-11-1974 J. Remmelink en Th.W. van Veen: Politieke delicten.

30-01-1975 W.K. van Dijk: Het ziektebegrip in de psychiatrie.

20-03-1975 B. Delfgaauw: Over zelfmoord.

29-05-1975 Mw. F. Lindenbergh-van Hoorn en C. Kleiwerda: Eenzaamheid.

24-09-1975 Excursie naar de Dr. S. van Mesdagkliniek.

25-09-1975 Bespreking van de bij de excursie opgedane ervaringen.

27-11-1975 G. Overdiep: Voorbeelden van rechtvaardigingsgronden.

20-05-1976 H.K.E.M.G. Niessen: Problemen van drugspatinten. 
23-09-1976 J. Nijborg: De gevangenis, problemen vandaag en plannen voor morgen.

25-11-1976 J.P. Balkema: Ervaringen met studentengespreksgroepen in de gevangenis Norgerhaven.

17-02-1977 J.B. van Borssum Waalkes: De moeilijk plaatsbare psychiatrische patiënt.

02-06-1977 J.H.G.C. Elzinga: Politie en sociale interventie.

22-09-1977 Open discussie over de gijzelingsactie bij de Punt.

01-12-1977 R. Giel: De problemen van de Zuidmolukkers.

23-02-1978 C. Rümke: Het project Veendam, hulpverlening aan niet gemotiveerde ouders.

18-05-1978 J.B. van Borssum Waalkes en E. Meulenbelt: Voedselweigering en hongerstaking.

21-09-1978 H.P.J. Vos: Methadontoediening aan herö̈neverslaafden.

23-11-1978 A. Boerman: Forensische psychiatrie in Zweden.

08-02-1979 Mw. W.F. van Hattum: Ervaringen van een jonge advocate.

10-05-1979 H. Tadema: Forensische psychiatrie buiten het strafrecht.

27-09-1979 W. Goudsmit: Chemische castratie, de behandeling van sexuele deviaties met de geslachtsdrift dempende farmaca.

27-11-1979 G.J.A. Smale en T. de Boer: Het slachtofferproject van het Criminologisch Instituut.

14-02-1980 J.P. Balkema: De duur van de voorlopige hechtenis.

24-04-1980 J.L. van der Neut: Het wetsontwerp zededelijkheidsdelicten, met name over pornografie en exhibitionisme.

20-09-1980 A. Rengelink: Agressieve patiënten, die door psychiatrische inrichtingen worden geweigerd.

20-11-1980 J.A.R. Sanders-Woudstra: De betekenis van zedendelicten bij kinderen.

12-02-1981 W.K. van Dijk: De rechtspositie van patiënten in psychiatrische ziekenhuizen.

21-05-1981 A. Stoffers: Het inzagerecht in medische dossiers.

08-10-1981 J. Remmelink en W. Goudsmit: Over euthanasie, juridische, psychiatrische en ethische aspecten.

10-10-1981 K. van Tuinen: Gedachten over een behandelingsgevangenis.

25-02-1982 D.W. Steenhuis: Verschillen in straftoemeting.

22-04-1982 W. Buikhuisen: Onderzoekplannen met agressieve jongeren.

18-10-1982 Th.W. van Veen: Frustratie in de rechtspraak.

23-11-1982 H.H.W. Hogerzeil: Problemen rond de arbeidsongeschiktheid.

10-02-1983 J. Grootenboer: Jeugdpsychiater en/of kinderrechter.

16 
26-05-1983 T.A. Kijlstra en R.A. Huisman: Vragen naar alternatieven.

15-09-1983 A.B. Vast: Over seponeren.

24-11-1983 R. Bosma: Slachtoffers van delicten.

16-02-1984 K. van Tuinen: De rechtspositie van gedetineerden.

24-05-1984 H.J.C. van Marle: De behandelgevangenis in discussie.

27-09-1984 H.P.J. Vos: Moderne behandeling van drugspatinten.

22-11-1984 Mw. J.C.M. van der Geijn-Oliehoek en A. Rengelink: Over motivatie van grote, emotieverwerkende industrieën.

14-02-1985 J.J.J. Tulkens: De rol van het personeel in het gevangeniswezen.

09-05-1985 J. Dieckman: De bewaarder aan het woord.

26-09-1985 Th.H. van Haaren: Reclassering in de laatste decennia.

13-10-1985 Feest t.g.v.h. 30-jarige bestaan van het Lutje P.J.G. B. Delfgaauw hield een inleiding over "Verantwoordelijkheid".

13-02-1986 F. Klok: Problemen van de mobiele eenheden.

22-05-1986 Mw. J.M. Smilde: Demonstratie over training gesprekvoering voor juridische studenten.

25-09-1986 Mw. W.F. van Hattum en R. Bosma: De advocaat en de rechtbank.

18-12-1986 D.F.J. Hoekstra: Weigeren van psychiatrisch onderzoek door de verdachte.

26-02-1987 J.B. Wilberdink: Problemen van aids.

14-05-1987 J.H.G.C. Elzinga: De (rijks)politie in de schaduw van het regeeraccoord.

01-10-1987 D.F.J. Hoekstra en H.C.J. van Marle: De nieuwe wet tbs.

26-10-1987 L.C.M. Meijers: Over vrijheid.

11-02-1988 W.A. Wagenaar: De rol van de getuige in het strafproces.

19-05-1988 J.B. van Borsssum Waalkes: Problemen van de volksgezondheid.

22-09-1988 M.H. Cohen Stuart: Legalisme en psychiatrie.

24-11-1988 W. Goudsmit: Toepassing van hypnose in het (straf)proces bij getuigen.

16-02-1989 Th.W. van Veen: Over differentiatie van het gevangeniswezen.

25-05-1989 J.J.J. Tulkens: Electronisch toezicht.

21-09-1989 A.W.M. Mooij: Forensisch psychiatrische rapportage.

30-11-1989 K. van Tuinen en J.C.A. Weijmar Schultz: De F.P.K. te Assen.

22-02-1990 M. Wolters en A.H. Wijnberg: Ervaringen van begeleidende advocaten in de Dr.S. van Mesdagkliniek.

10-05-1990 F.A.M. Kortmann: Ethnische minderheden in het psychiatrisch ziekenhuis. 
04-10-1990 J. Remmelink: Over leven en dood in het strafrecht.

16-10-1990 Feest t.g.v. het 35-jarige bestaan van het Lutje P.J.G. L.C.M. Meijers en A.W.M. Mooij hielden inleidingen over: enige aspecten van de tbs, in het bijzonder over rapportage-problematiek bij oplegging en verlenging.

21-02-1991 L.C.M. Tigges: Actuele problemen in de tenuitvoerlegging van de tbs.

18-04-1991 Excursie naar Huize Veldzicht te Avereest.

26-09-1991 Th.W. van Veen: Zouden wij in het jaar 2000 de tbs invoeren?

19-12-1991 H.P. den Daas: Communicatiestoornissen bij psychiatrische expertise.

27-02-1992 Mw. Th. Drost: De beslissing van de rechter over het wel of niet verlengen van een tbs.

07-05-1992 B.P.R. Gersons: Intensieve behandeling van de post-traumatische stressstoornis; ervaringen bij politiemensen.

01-10-1992 Mw. M. Winkels: De binnenkooi, onderzoek op de afdelingen intensieve zorg binnen de tbs.

26-11-1992 J.B. Balkema: Het werk van de penitentiaire kamer.

25-02-1993 J.B. van Borssum Waalkes: Het donker veld tussen psychiatrie en recht.

17-04-1993 Excursie, samen met het Psychiatrisch-Juridisch Gezelschap, naar Rekken.

13-05-1993 J.Ph. Eggink: Kan de kinderbescherming wel beschermen.

25-11-1993 Mw. A. Korf-Van der Veen en G.H.F. van der Most: Forensische aspecten van de kinder- en jeugdpsychiatrie.

17-02-1994 A.J. Tholen: Het beoordelen van wilsbekwaamheid bij psychiatrische patiënten.

19-05-1994 A.H. Wijnberg: Het geweten van de advocaat.

29-09-1994 O. de Haas: Het 4-factorenmodel.

24-11-1994 F.J.M. Hoogenboom: Nieuwe ontwikkelingen bij de alternatieve straf.

Wij kunnen ons de vraag stellen wat er aan deze lijst heeft ontbroken. Om te beginnen valt op dat de problemen van de gedetineerde vrouw er niet op voorkomen; dit komt misschien doordat de vrouwengevangenis nog ver weg is en omdat er in de Dr. S. van Mesdagkliniek uitsluitend mannen werden en worden behandeld. Ook de huizen van bewaring kregen tot nu toe te weinig aandacht. Van de thans actuele vraagstukken ontbreekt verder, behalve dat van 
de Molukkers met hun speciale problematiek, ook dat van de allochtonen in onze samenleving en in de inrichtingen.

Er is sinds de oprichting van het Lutje veel veranderd en de veranderingen gaan door. Het aantal reclasseringsverenigingen werd drastisch beperkt en gecentraliseerd. De functie van het psychiatrisch ziekenhuis is in de afgelopen veertig jaar veranderd, net als het opnamebeleid voor zeer agressieve patiënten. In Assen verrees de nieuwe forensisch- psychiatrische kliniek. Verder wordt de Dr.S. van Mesdagkliniek weer uitgebreid. Er zijn bovendien nieuwe vormen van nazorg ontstaan, zoals beschermde woonvormen voor chronisch psychiatrische patiënten. Zowel de intra-murale als de extra-murale behandeling is aan de hedendaagse opvattingen aangepast, maar in principe niet wezenlijk veranderd.

Betrekkelijk nieuw is (zie ter vergelijking van Rooy, 1957) het grote aantal periodiek of chronisch psychotische gedetineerden in de huizen van bewaring, de gevangenissen en de forensisch-psychiatrische klinieken. Nieuw is verder, vooral voor de huizen van bewaring, het zeer grote cellentekort. Dit tekort ontstond ondanks versnelde nieuwbouw. Daarnaast stellen zowel het drugsprobleem als de groeiende georganiseerde misdaad ons voor zeer moeilijk beheersbare opgaven. Over de oplossing van deze problemen zijn de deskundigen het nog niet eens, mede omdat hierbij ook wereldbeschouwelijke problemen een rol spelen. Bezuinigingen beperken bovendien in toenemende mate de mogelijkheden van zorg en behandeling.

Het is de gewoonte om tegen het einde van de eeuw voorspellend naar de nieuwe eeuw te kijken. Er worden door sommigen al plannen voor het jaar 2000 en de tijd daarna gemaakt. Ik durf mij daar niet aan te wagen.

Dat reële gevaren het voortbestaan van de mens bedreigen, kunt u dagelijks in de media horen, zien en lezen. Het zal zeer moeilijk worden om met de onverantwoorde verkwisting van grondstoffen te stoppen, de overbevolking zal blijven toenemen en de tegenstelling tussen arm en rijk zal steeds groter worden, zowel op nationaal als op mondiaal niveau. Dit leidt weer onvermijdelijk tot migratie en tot verdere groei van armoede- en welstandscriminaliteit en tot toename van het internationaal terrorisme. Misschien realiseren wij ons nog steeds te weinig dat crimineel gedrag gezien moet worden als spiegel van wat er in de samenleving leeft: wordt de samenleving harder en agressiever dan wordt de criminaliteit dat ook. De vraag is òf en hoe wij deze wereld leefbaar kunnen houden. Leefbaar in sociaal, materieel en mentaal opzicht.

Over één gevaar wordt weinig geschreven, namelijk over de de-humanisering van de samenleving, waarvoor de etholoog Konrad Lorenz (1983) in één van zijn laatste boeken gewaarschuwd heeft. Het is te vrezen dat hij gelijk heeft. 
De problemen waarvoor wij gesteld worden vereisen zeer veel inzicht en inspanning, wederzijdse acceptatie, en de bereidheid om samen te werken. Daarvoor is een blijvende dialoog noodzakelijk. Op ons gezamenlijke werkterrein kan het Lutje een bijdrage leveren, met name ook voor de toekomst, in een bredere context.

Het Lutje P.J.G. is veel dank verschuldigd aan Wim Havinga, Mart Wuijts-Lenstra en Emma ten Broek-Scholte. Zonder hun toegewijde hulp had het Lutje niet kunnen functioneren.

\section{Literatuur:}

J.M. van Bemmelen: Van zedelijke verbetering tot reclassering, dissertatie Groningen, 1923.

Kraus: De huidige ontwikkelingsfase van de geestelijke gezondheidszorg in ons land. Maandblad voor de geestelijke volksgezondheid 11, p. 208-228, 1956.

Rooy, H. van e.a.: Criminologisch onderzoek betreffende recidivisten en ter beschikkinggestelden. Studie- en Voorlichtingscentrum van het Ministerie van Justitie, 1957.

Psychiatrisch-Juridisch Gezelschap: Gedenkboek 1907-1957, Amsterdam, 1957.

Meyer Sluyser: Niemand die het antwoord weet, Kosmos, Amsterdam, 1967.

K. Lorenz: Der Abbau des Menschlichen. München Zürich, 1983.

J.W. Reicher, J. Remmelink en TH.W. van Veen: Verantwoordelijk voor mensen, Gouda

Quint, 1985. 